\title{
Power theory of exchange and money
}

\author{
Yaroslav Stefanov ${ }^{1}$
}

\begin{abstract}
Modern exchange theories model a large market, but do not explain single exchange. The paper considers the phenomenon of single exchange and formulates the general exchange problem in the form of a system of two equations, subjective and objective. Subjective equilibrium is given by the Walras-Jevons marginal utility equation. Objective equilibrium equations by Walras and Jevons are averaged over all transactions in the market and can only give a rough general picture without explaining the specific price of an individual exchange. An exchange micro-condition must be found that, when averaged, will give the Walras market equilibrium macro-condition. The study of the internal structure of exchange leads to the need to consider power. The concept of generalized power is introduced. It is generalized power that serves as the primary comparable and measurable objective basis of exchange. The power theory of exchange provides the objective price-equation. It is demonstrated that money is a measure of generalized power in exchange and a certification of generalized power in subsequent exchanges. The proposed theory is able to uniformly explain any exchange, including a single one, which is impossible with the existing theories of exchange.
\end{abstract}

Keywords: exchange, exchange theory, money, money theory, power JEL classification: A10, A13, A14, D00, D41, D46, D51, E40, G00, Z13

1 Moscow State University; E-mail: yrsstf@gmail.com. 


\section{Introduction}

Many authors, regardless of their scientific views, assign a key role to exchange in economic research. In Karl Marx's book Das Kapital, the second chapter is dedicated exclusively to exchange. (Marx 1887) Ludwig von Mises, a representative of a completely different movement and an ideological opponent of Marx's, wrote that "the exchange relation is the fundamental social relation". (Mises 1998) According to William Stanley Jevons: "It is impossible to have a correct idea of the science of Economics without a perfect comprehension of the Theory of Exchange". (Jevons 1924)

Theorists have achieved remarkable results in constructing models of market exchange under conditions where a large volume of transactions is conducted (hereinafter "large market"). However, in the case of a simple discrete exchange, the existing approaches do not provide a complete explanation. The central element of modern economics is the Walrasian general equilibrium model, which is designed for a large market, when supply and demand are generated by many buyers and sellers. But this model does not explain the case of a simple exchange. At the beginning of his book, Walras mentions that " $\mathrm{Of}$ course, our theory should cover all such special cases.... market.. in which there is a single buyer, a single seller... ", but later in the book he deals only with "exchange as it arises under... competitive conditions [of the large market]" (Walras 1954). As Alfred Marshall (1890) noted "in a casual bargain that one person makes with another..., there is seldom anything that can properly be called an equilibrium of supply and demand". Francis Ysidro Edgeworth (1881) was more defined: "Contract without competition is indeterminate". To obtain an unambiguous solution of exchange problem, these theories refer to the conditions caused by the large market. Franco Donzelli wrote in detail about the role of these conditions in the article "Negishi on Edgeworth on Jevons's law of indifference, Walras's equilibrium, and the role of large numbers: a critical assessment" (Donzelli 2011) so I will not explore the issue in depth here. Instead, I will consider only 
those aspects that are important for further reasoning. The aim of the paper is to build a complete model that will be able to describe any exchange uniformly, irrespective of whether it occurs on a large market or if it is a one-off event.

Part 1 considers the important role of the large market in existing exchange theories. Part 2 presents the formulation of the exchange problem as a system of two equations with two unknowns. Then one of the equations is determined. Part 3 examines the concept of power and introduces the concept of generalized power. The application of these concepts in the case of exchange is introduced. Part 4 outlines a power theory of exchange and determines the second equation. Part 5 presents a power theory of money.

\section{Role of the large market on exchange theories}

It is best to start by considering the assumptions of modern exchange theories, which are dependent on the influence of the large market. According to Walrasian exchange theory, prices are determined by the competitive market as a result of supply-demand equilibrium. In particular, Walras illustrates his position by the example of trade in wheat: the price "does not result either from the will of the buyer or from the will of the seller or from any agreement between the two" because price is a "natural phenomenon." (Walras 1954) This quote clearly shows the difference between the cases of a simple exchange and a large market, because in a simple exchange, the exchange rate depends precisely on the will of the participants and on their agreement.

Under an alternative approach, the Jevons exchange theory, the additional condition is the "law of indifference", which alone allowed Jevons to construct a system of two equations. He wrote that "the two equations are sufficient to determine the results of exchange; for there are only two unknown quantities concerned, namely, $\mathrm{x}$ and $\mathrm{y}$, the quantities given and received." (Jevons 1924) Later, Edgeworth, writing on the Jevons equations, criticized the axiomatic introduction of an additional condition and offered his 
way of solving the problem through the introduction of "perfect competition," which is in fact the large market. (Edgeworth 1881) Despite subsequent attempts by Takashi Negishi to defend Jevons' conclusions, (Negishi 1989) they were challenged by Donzelli. Donzelli wrote: "The failure of Negishi's attempt confirms, in the last analysis, that Edgeworth's results cannot be improved... stronger results depend on the special assumptions adopted." (Donzelli 2011).

Both Walras and Jevons' models are based on marginal utility theory (MUT), where exchange is viewed through the subjective estimations of the participants. In order to find a solution in each model it was necessary to add objective conditions to the subjective equations of marginal utility. To Walras, this additional condition was the law of one price caused by supply-demand equilibrium on the market. As for Jevons, when analyzing his equations, Edgeworth demonstrated that the incorporation of "perfect competition" with a large number of actors into the model allows one to obtain a single solution. In other words, to solve the problem, Edgeworth was forced to go beyond the only subjective assessment of utility and to introduce an objective factor, perfect competition, which is the result of a social phenomenon, a large market. The necessity of adding objective circumstances to subjective assessments is not accidental, as will be seen later. In addition, it will be emphasized that the mathematical form of the corresponding Walras and Edgeworth-Jevons price-equations does not depend on the parties involved in the exchange (at the same time, their equations for marginal utility depend on the parties of exchange in an explicit form). These equations set a uniform price for the entire market. But in reality, even in a large market, the personalities of the participants in the single exchange can influence the price, and in the same market, different prices are possible in different exchanges.

So far, I have only focused on the models that are based on MUT. However, there is also another approach, which is based on the labor theory of value (LTV). I will cover it later. I start by considering a simple exchange in general terms. 


\section{Two conditions, two equations}

A simple single exchange is the interaction of two actors (participants, subjects, parties, commodity owners) whereby negotiation (bargaining) is conducted and the ratio of exchange is defined. After an agreement has been reached, objects (goods) of exchange are transferred mutually in specified amounts. The concept of a transfer will require special attention later.

If two participants $\mathrm{H} 1$ and $\mathrm{H} 2$ exchange objects $\mathrm{O} 1$ and $\mathrm{O} 2$, then their common task is to determine the number $\mathrm{x}$ of objects $\mathrm{O} 1$ and the number $\mathrm{y}$ of objects $\mathrm{O} 2$ that will be transferred mutually in the course of exchange. Exchange is thus a problem with two unknowns. When they bid, the participants in the exchange are setting the specific values of the variables $\mathrm{x}$ and $\mathrm{y}$ with a view to solving the problem together.

A twofold interpretation of the factors of the object of exchange has formed gradually since the time of Aristotle. On the one hand, the exchanged items can satisfy human needs, be useful and thus have value for individuals as object of utility. This factor is called use value. On the other hand, objects can be exchanged for other things, and thus they have value for individuals as a means of obtaining other goods. This factor is called exchange value. Both factors have roles to play in exchange and both influence its outcome. Researchers have explained them in different ways. For example, to Marx, the rationale of exchange value is materialized labor. To Walras, it is scarcity. Böhm-Bawerk deeply studied the question of the duality of exchange and use values. (1886)

Exchange value manifests in the interaction between the exchanging parties as a quantitative ratio. It arises as a compromise between the interests of the participants in the exchange. Exchange value is the result of economic interaction between two members of society. This result has an objective basis because when specific values are 
established during exchange, a decision is made jointly by two participants, each of whom is forced to consider the wishes of the other. In addition, other external circumstances of a social nature may exercise an influence on the ratios of exchange. For example the presence of a large number of sellers in the market can change the exchange ratio compared to the case when there are no other sellers. Therefore, in the case of exchange value, there is some objective condition of exchange which is established during an interaction between two subjects. If exchange is considered a solution to a problem with two unknowns, then the circumstance of exchange value can be represented in a very general form as a function $\mathrm{OB}$ that imposes restrictions on the variables $\mathrm{x}$ and $\mathrm{y}$.

$\mathrm{OB}(\mathrm{x}, \mathrm{y})=0$ - the equation of objective equilibrium or price equation. (1)

The OB function is objective in nature, that is, it does not reflect the purely personal assessments of each side but instead arises from the interaction of the parties, and it may depend on social circumstances.

The use value that participants can extract from the objects of exchange is subjective. Participants must take this factor into account when exchanging since everyone seeks to benefit themselves. Thus, use value can be understood as a subjective condition of exchange that each participant estimates for themselves. However, these estimates also affect the exchange and set its conditions. If exchange is construed as a solution to a problem with two unknowns, then the circumstance of use value can be represented in a very general form as a function SU that imposes restrictions on the variables $\mathrm{x}$ and $\mathrm{y}$

$\mathrm{SU}(\mathrm{x}, \mathrm{y})=0-$ subjective equilibrium equation or quantity equation. (2)

Thus, two conditions of exchange can be discerned, one that is objective (public) and another that is subjective (personal). Each condition imposes a restriction on the 
unknown variables. Moreover, by their nature, these conditions are independent: whatever the personal preferences and needs of each subject (condition of the SU), they collide with the opposite interests of the other in the course of bargaining, forcing the two to develop a minimally objective compromise (condition OB).

Mathematically, finding the values of two unknowns requires two independent equations that restrict the two variables. One equation gives the ratio of the variables (price), and the second determines the absolute solution (final amount). Therefore, proceeding from general considerations, one can expect that the participants in the exchange must solve a system of two equations that have already defined before, connecting the variables $x$ and $y$.

$\left\{\begin{array}{l}O B(x, y)=0 \\ S U(x, y)=0\end{array}\right.$

This system of equations may not have solutions, and then the exchange will not take place.

What are the equations in system (3)? Earlier, I discussed two models of exchange that are based on MUT. These models propose equations that describe the subjective conditions of exchange as they compare the subjective marginal utilities for the parties. Moreover, as Walras showed, the ideologically different models of Jevons and Walras are mathematically identical. Walras wrote that for the case of of exchange between two individuals "Jevons's formula is identical with our own, except that he used quantities exchanged where we use prices." (Walras 1954) Therefore, the MUT provides one independent equation for comparing marginal utility in exchange. Consider the Jevons equation in the form given by Edgeworth, (1881) 
$\frac{\varphi_{1}(a-x)}{\psi_{1}(y)}=\frac{\varphi_{2}(x)}{\psi_{2}(b-y)}(4)$

where $\varphi_{1}$ and $\psi_{1}$ denote the marginal utilities of two products for participant $\mathrm{H} 1$, and this participant surrenders $x$ units of one product out of a total of $a$ that they hold. In return, they receive $y$ units of another product. The functions $\varphi_{2}$ and $\psi_{2}$ have the same meaning for participant H2. Since this equation imposes a condition on the utility ratios for the two participants, I can employ (4) as a subjective equilibrium equation $\mathrm{SU}(\mathrm{x}, \mathrm{y})$. To maintain consistency with chosen form, I rewrite it as

$S U(x, y)=\varphi_{1}(a-x) \psi_{2}(b-y)-\varphi_{2}(x) \psi_{1}(y)=0$

Before continuing, it should be noted that both Walras and Jevons proposed their variants of equations as the first equation $\mathrm{OB}$ in this system (3). However, the equations they proposed do not describe the conditions of this particular exchange, but represent entire market generalizations. Formally, this can be seen from the mathematical representations of these conditions. In case of Jevons it is $\frac{d x}{d y}=\frac{x}{y}$, and in case of Walras it is $F_{a}\left(p_{a}\right)=$ $F_{b}\left(\frac{1}{p_{a}}\right) \frac{1}{p_{a}}$, or in terms of $\mathrm{x}$ and $\mathrm{y} F_{a}\left(\frac{y}{x}\right)=F_{b}\left(\frac{x}{y}\right) \frac{x}{y}(5.2)\left(\mathrm{F}_{\mathrm{a}}\right.$ and $\mathrm{F}_{\mathrm{b}}$ represent demand of goods $\mathrm{A}$ and $\mathrm{B}, \mathrm{x} / \mathrm{y}$ is price). No indexes of participants $(1,2)$ are involved in these equations, in contrast to the equations of marginal utility, where these indices are explicitly present (for example see (4)).

If the general system of equations (3) is written more rigorously, then both the participants $(1,2)$ of the exchange and the objects being exchanged $(A, B)$ must be explicitly present in it as parameters:

$$
\left\{\begin{array}{l}
O B_{1, a, 2, b}(x, y)=0 \\
S U_{1, a, 2, b}(x, y)=0
\end{array}\right.
$$


These parameters are explicitly represented in the marginal utility equations proposed by Walras and Jevons. However, another exchange condition presented by each of these authors does not contain the specified parameters 1 and 2. So, Jevons simply axiomatically introduces the formula of the "law of indifference", and Walras gives reasoning when some supply-demand curves are averaged over the entire market, and thus a common price for all is obtained. In both models, the price equation is independent on individual exchange. But in reality, even in a large market, the prices of individual exchanges can vary and the correct model should reflect this fact. I am not suggesting here that the terms they proposed were incorrect. In fact, Jevons' condition was wrong, and Walras' condition was true. However, these were not the conditions of this particular exchange, but the market conditions averaged over variables 1 and 2 .

What can the first OB equation in system (3) be? LTV might come into play. According to LTV, when they engage in exchange, the parties compare the amount of socially necessary labor that is needed for the creation of the exchange objects. The condition of the exchange is the equal content of labor $\mathrm{T}$ in the objects of exchange. In other words, the exchange will occur if

$\mathrm{T}(\mathrm{x})=\mathrm{T}(\mathrm{y})$, where $x$ and $y$ are the quantity of the exchange items $\mathrm{O} 1$ and $\mathrm{O} 2$. (6)

This equation offers an objective criterion for exchange and could be the first equation in system (3). However, the LTV is incomplete, that is, it is incapable of explaining every possible exchange uniformly, as any counterexample proves. Marx gave one such example in Das Kapital. He wrote: "Objects that in themselves are no commodities, such as conscience, honour, \&c., are capable of being offered for sale by their holders, and of thus acquiring, through their price, the form of commodities." (Marx 1887) Here, Marx tried to escape a predicament - the content of labor is not found in the named objects of exchange, which means, according to his logic, that those objects cannot be exchanged. 
However, in reality, they do become objects of exchange, which forced Marx to seek explanations beyond the LTV. There are numerous examples of instances where no labor can be found in the objects of exchange, up to cases where money is paid for deliberate inaction, that is, the guaranteed absence of labor. Thus, LTV is not suitable for solving the exchange problem. To discover the condition that is necessary to compose a complete system of equations, I propose to regard exchange in more detail.

Consider the following proposition: both the exchange value and the use value of a desired object become available to the participants in exchange only when the objects of exchange are at the disposal of each participant. As long as an item does not belong to a person, they cannot access any of the value in that item. Within the framework of market relations, it is impossible to exchange or use an object that a person does not control. Marx wrote about it as follows: "Um diese Dinge als Waaren auf einander zu beziehn, müssen die Waarenhüter sich aufeinander als Personen beziehn, deren Willen ein Dasein in jenen Dingen hat, sodass Jeder nur mit seinem Willen und dem Willen des andern, beide also nur mit ihrem gemeinschaftlichen Willen sich die fremde Waare aneignen, indem sie die eigne veräussern und die eigne veräussern, um sich die fremde anzueignen." (In order to relate these [exchanged] things to one another as commodities, the guardians of commodities must relate to one another as persons whose will disposes of these things, so that each acquires the foreign commodity only with his will and the will of the other, both therefore only with their common will can appropriate someone else's goods, alienating their own.) (Marx 1867) Marx notes the need for an ability to dispose, an ability to fulfill the will of the commodity owner in relation to the commodity or, as I will discuss later, the necessity of "finding the commodity in the power" of the commodity owner. Here, I need to discuss the concept of power in more detail.

\section{Power and Generalized Power}


There are several approaches that look at the concept of power from different angles. Here, the situation with different views on the concept of power in sociology and political science is to some extent similar to the situation with different approaches to utility in economics, when different authors offer different definitions when they consider this phenomenon from various perspectives. (Keller 2015) I will briefly recall now the different points of view on the concept of power.

Max Weber defined power as "the probability that one actor within a social relationship will be in a position to carry out his own will despite resistance, regardless of the basis on which this probability rests." (Weber 1957) The works of Harold D. Lasswell, Abraham Kaplan, Robert Dahl, Dorwin Cartwright, Steven Lukes, and Anthony Giddens presents a concept according to which "power arises in those social interactions where one of the subjects has the ability to influence the other, overcoming his resistance." (Ledyaev 2015) In another approach, followed by Talcott Parsons and Hannah Arendt, "power is viewed as a collective resource, as the ability to achieve some public good; the legitimate nature of power is emphasized, it's belonging not to individuals, but to groups of people or society as a whole." (Ledyaev 2015)

Each of these approaches attempts to explain the mechanisms for exercising power through either coercion or agreement. To the present ends, the mechanisms of power are less important than a description of power in terms that are applicable to exchange. The quote from Marx above indicates that the notions of will and disposal are likely to prove useful. Now, an appropriate definition of power can be given. Nothing new has to be invented for this purpose. I need only highlight and slightly transform part of the quote by Weber: power is the ability to realize (exercise) the will (the ability to dispose) of the subject in relation to the object.

Power is often described in comparative terms. Phrases like "they have a lot of power" or "this person has much more power than that person" can often be heard. Some 
researchers have argued about the measurability of power. Thus, in the works of Lasswell, Kaplan and Mills, (Mills 1956) the model of power is a zero-sum problem, that is, "there is a fixed 'quantity' of power in any relational system and hence any gain of power on the part of A must by definition occur by diminishing the power at the disposal of other units, B, C, D." (Parsons 1963) Thus, power turns out to be quantitatively measurable, and in fact the "law of conservation of power" is proclaimed. I adopt a similar quantitative approach, albeit without the conservation law (perhaps Parsons' consideration of this law is based on the kind of misunderstanding of the work of the aforementioned scientists, as shown by David A. Baldwin, 1971). Note that the word "probability" used by Weber in his definition of power is in agreement with the quantitative measurability of power. However, following Peter M. Blau, I used "ability" in the definition. The reason is that mathematical value of probability cannot exceed one. However, in the case of power, the general measuring scale cannot be limited because one power can always be more than another. As for the term "ability" in the definition of power, perhaps an example from physics would be appropriate, when energy is defined as the ability to do work. According to Bertrand Russell "the fundamental concept in social science is Power, in the same sense in which Energy is the fundamental concept in physics" (Russell 2004) Jonathan Hearn studied in detail the analogy between social power and physical energy. (Hearn 2012)

It should be clarified that I am not mentioning economic theories of power here, since they do not offer the idea of measurability of power. For example, the evolutionary chain of theories of the firm (Alchian and Demsetz, Coase and Williamson, Hart and Moore) significantly address the issues of power relations, but power is not a measurable parameter.

I propose to return to the concept of transferring an object between exchange participants. Transferring is key for the parties to gain access to the benefits that they want. How is the transfer actuated? First of all, as Marx rightly noted, the will of [the 
parties] disposes... of things [objects of exchange]. In other words, the precondition for exchange is that the will of the participant can dispose of their object of exchange. How does the will of this subject relate to the object before and after the exchange? The nature of exchange items can vary. Material and informational objects (or more generally: tangible or intangible objects) can be exchanged, as can activity and inactivity. When it comes to the possibility of exercising the will in relation to an inanimate object, it is possible to speak of a right of ownership in relation to the object. However, in reality, items are sometimes exchanged that are not owned by the participants. For instance, a thief may well exchange a stolen object, even though the thief does not have ownership rights. The thief can dispose of the object without those rights because the object is in their power and they have the ability to exercise their will vis-a-vis the object, even without legal rights. The implication is that it is more accurate to speak not of ownership but of finding an object in power. In general one can regard "ownership as the power to exercise control." (Grossman and Hart 1986) Grossman and Hart also refer in the same article to the Oliver Holmes' quote, which more fully expresses the idea: "the owner is allowed to exercise his natural powers over the subject-matter". (Grossman and Hart 1986) In the course of an exchange, objects must be swapped and a transfer must occur. In this way, the object passes from the power of one party to the control of another. Then, each participant loses the ability to dispose of their objects. However, they are able to dispose of, that is, to exercise their will in relation to the received objects.

The case is different when activity forms the object of exchange. Suppose that a worker transacts in labor at a construction site. In this case, every working day, for eight hours, the worker does not control their activities. Instead, a foreman does. By giving instructions to subordinates, the foreman exercises their will in relation to the subordinates. The foreman says what needs to be done; the worker obeys and performs the necessary work. Thus, within the framework of the contractual relationship that has arisen in the course of the exchange, the foreman exercises power over the worker. For eight hours, the worker is under the power of the foreman, who can dispose of his 
activity. In general "After the exchange, power is in the hands of the capitalist, and its monetary equivalent in the pockets of the worker." (Palermo 2016)

In exchanges of both material objects and activities, transfer takes the form of a mutual transmission of the object of exchange to the power of the other party. To emphasize the unified nature of the events that transpire during the exchange, I use the term "generalized power," that is, the ability of the subject to exercise their will in relation to the object both in the case of material or informational objects and in the case of activities. Then, "transfer" in exchange is the mutual transfer of objects to the generalized power of the other party.

In general, no fundamental obstacles prevent the extension of the concept of power into the concept of generalized power. Generalized power includes both power over people and power over things or information. Generally speaking, the two cases differ only in the object to which the human will is applied. The ability to dispose of a material or informational object, power over such an object, means that a person can exercise their will in relation to an object and do what they want with it. The ability to control the activities of a person, power over a person, means that one can exercise one's will in relation to another, a subordinate, and give orders that the subordinate will obey. Walras wrote: "The object of bringing the human will to bear upon natural forces, that is to say, the object of relations between persons and things, is the subordination of the purpose of things to the purpose of persons. The object of exercising the human will on the will of others, in other words, the object of relations between persons and persons, is the mutual co-ordination of human destinies." (Walras 1954) Probably it would be logical to supplement this statement of Walras by saying that in the case of human relations, similar to the case of relations between persons and things, the object of exercising the human will is the subordination of the purpose of one person to the purpose of another person. In both cases, power is the ability to actuate will. In fact, possession (of an object) and dominion (over a person) merge naturally because both concern the application of the 
will of an individual to some object. Power is exercised in both cases, and it is directed at either objects that do not have their own will (material or informational objects) or to objects that do (people). This shows the natural essence of the term "generalized power," which combines different manifestations of power.

It follows that, at first, the object of exchange $\mathrm{A}$ is under the generalized power of the first participant in the exchange, H1. After negotiations with the second participant, H2, and the determination of the parameters of exchange between objects $\mathrm{A}$ and $\mathrm{B}$, the two are transferred. At this moment, the generalized power of $\mathrm{H} 1$ over A disappears, as does the generalized power of $\mathrm{H} 2$ over $\mathrm{B}$. There immediately arises a new generalized power of $\mathrm{H} 1$ over B and, accordingly, of $\mathrm{H} 2$ over A. Interestingly, power is not transferred in the same way as material objects - it does not pass physically from hand to hand. After all, the power of exchange participant $\mathrm{H} 1$ over object $\mathrm{A}$, which exists before the exchange, is not exactly the same power as that of participant $\mathrm{H} 2$ over object $\mathrm{A}$, which appears after the exchange. (It is important to note in parentheses that the behavior of generalized power in exchange is very similar to the behavior of utility, because the utility of the same object after the exchange is a different utility than it was before the exchange.) Nevertheless, there is a transfer of power. Initially, H1 had power over A. Now, $\mathrm{H} 2$ has power over A. It turns out that the true essence that is transferred at the moment of exchange is generalized power. Only after the transfer of generalized power can the participants in the exchange consume or exchange the received objects. Therefore, in the course of exchange, the transfer of power is primary vis-à-vis the transfer of use value and exchange value. The possibility of command or power must be transferred before the subject may enjoy the benefits that the object of exchange embodies.

It emerges that generalized power plays a key role in the second stage of exchange, the moment of transferring objects. Now, in order to reveal the role of power in establishing the proportion of exchange, I turn to the bargaining process. Let's model a standard 
negotiation. Suppose that two individuals, $\mathrm{H} 1$ and $\mathrm{H} 2$, engage in exchange. H1 offers goods $\mathrm{A}$, and $\mathrm{H} 2$ offers goods $\mathrm{B}$. The bargaining proceeds along the following lines:

1. $\mathrm{H} 1$ offers an exchange ratio of $2 \mathrm{~A}$ for $7 \mathrm{~B}(2 / 7 \approx 0.28)$

2. $\mathrm{H} 2$ proposes $3 \mathrm{~A}$ for $8 \mathrm{~B}$ instead $(3 / 8 \approx 0.37)$

3. $\mathrm{H} 1: 3 \mathrm{~A}$ for $10 \mathrm{~B}(3 / 10=0.30)$

4. $\mathrm{H} 2: 3 \mathrm{~A}$ for $9 \mathrm{~B}(3 / 9 \approx 0.33)$

5. H1 accepts the offer.

The numbers in brackets indicate proportions (the number of $A$ is divided by the number of $\mathrm{B}$ ). In the course of bargaining, $\mathrm{H} 1$ is trying to lower the ratio and $\mathrm{H} 2$ is trying to increase it. In bargaining by the method of successive approximations, a certain final ratio is sought that will suit both parties. Different quantities of goods A and B are equated. These goods may not have anything in common. However, in the course of exchange, some commonality is found and compared quantitatively. So, what is measured or compared during the bargaining process? Is it labor, as Marx claimed? Or is it scarcity, as Walras wrote? As shown above, generalized power is mutually transferred during the exchange. The transfer of the object is the transfer of power over the object, which means that it is precisely generalized power that must be compared during the bargaining process. $\mathrm{H} 1$ and $\mathrm{H} 2$ compare what they transfer to each other and this is exactly and exclusively the generalized power. Moreover, generalized power must be compared before the exchange. After the exchange, other generalized powers will emerge on both sides.

Apparently, it is more important for an individual to measure the loss of what they had before the exchange than to evaluate their gains from it. Aristotle, in his analysis of exchange, wrote that "what belongs to us and what we give away always seems very precious to us." (Aristotle 1906) Kahneman and Tversky's well-known prospect theory later explained the relative importance of loss and gain in subjective assessments. The 
theory posits that "the disadvantages of a change loom larger than its advantages, inducing a bias that favors the status quo" (Kahneman 2011) (this phenomenon is called loss aversion). Therefore, assessing the loss of generalized power turns out to be the most important task of a participant in an exchange. It appears that the participants in the exchange must mutually evaluate how much generalized power each will lose before they can reach an agreement.

In view of the foregoing, I believe that while bargaining, participants compare the generalized power that they would lose as a result of a given exchange. As noted earlier, I proceed from the assumption that power is measurable, that is, that the generalized power $\mathrm{B}$ of the exchange participant $\mathrm{H}$ over the object of exchange $\mathrm{O}$ can be represented by a positive number

$\mathrm{B}=\mathrm{B}(\mathrm{H}, \mathrm{O})$, where $\mathrm{B}>=0$.

Later, it will be seen that there is a direct way to measure and quantify generalized power. Therefore, this assumption is not just an analytical prop but also a mechanism that exists in actuality. If the bargaining process set out above is represented through the function $\mathrm{B}$, the following sequence of estimates emerges:

1. B $(\mathrm{H} 1,2 \mathrm{~A})<=\mathrm{B}(\mathrm{H} 2,7 \mathrm{~B})$ - an estimate made by $\mathrm{H} 1$

2. B $(\mathrm{H} 1,3 \mathrm{~A})>=\mathrm{B}(\mathrm{H} 2,8 \mathrm{~B})$ - an estimate made by $\mathrm{H} 2$

3. B $(\mathrm{H} 1,3 \mathrm{~A})<=\mathrm{B}(\mathrm{H} 2,10 \mathrm{~B})$ - an estimate made by $\mathrm{H} 1$

4. $\mathrm{B}(\mathrm{H} 1,3 \mathrm{~A})>=\mathrm{B}(\mathrm{H} 2,9 \mathrm{~B})$ - an estimate made by $\mathrm{H} 2$

5. B $(\mathrm{H} 1,3 \mathrm{~A})<=\mathrm{B}(\mathrm{H} 2,9 \mathrm{~B})$ - agreement $\mathrm{H} 1$

Here, each estimate reflects the interests of the participants in the exchange in receiving more than what they give. Successive comparisons lead to two inequalities, 
$\mathrm{B}(\mathrm{H} 1,3 \mathrm{~A})>=\mathrm{B}(\mathrm{H} 2,9 \mathrm{~B})$

B $(\mathrm{H} 1,3 \mathrm{~A})<=\mathrm{B}(\mathrm{H} 2,9 \mathrm{~B})$,

whence it follows that

$\mathrm{B}(\mathrm{H} 1,3 \mathrm{~A})=\mathrm{B}(\mathrm{H} 2,9 \mathrm{~B})$ - exchange condition.

Thus, the exchange occurs only when the parties assess the generalized powers that they have in relation to the objects of exchange as being equal. Then, in the general case, the exchange condition is $\mathrm{B}_{1}(x)=\mathrm{B}_{2}(y)$ where $\mathrm{Bi}_{1}(x)=\mathrm{B}(\mathrm{H} i, x)$.

\section{A Power Theory of Exchange}

I have arrived at the power theory of exchange. The quantity of generalized power is the measurable basis of exchange. It should be noted that many sociologists have already highlighted the fundamental role of power in exchange. For the most part, these scientists considered not market exchange but social exchange, of which market exchange turns out to be a special case. In this approach, the concept of exchange extends beyond our framework into the more general problem of exchanges of values in society. These theories examine "the exchange of various types of activity as the fundamental basis of social relations on which various structural formations are based." (Kuznetsov 2012) The integration of power into the theory of social exchange is presented in the works of Peter Blau, George Homans and Robert Emerson. Peter Blau wrote that "power refers to all kinds of influence between persons or groups, including those exercised in exchange transactions, where one induces others to accede to his wishes by rewarding them for doing so." (Blau 1964)

Some researchers have noticed the role of power in establishing the proportion of exchange, including in economic contexts. Thus, Emerson, summarizing the findings of 
several researchers, wrote: "Within economics proper, much discussion of indeterminacy in the $x / y$ ratio concludes that it is a problem of power." (Emerson 1976) Furthermore, in analyzing the influence of power on the ratio of economic exchange, he concluded that the public power available to one of the parties to an exchange often skews the ratio in their favor. Emerson wrote about the emergence of an "unbalanced ratio" of exchange under the influence of power. He meant that if one side, party A, wield social power over another, party $\mathrm{B}$, then the exchange ratio is likely to favor the first. However, this supposedly unbalanced ratio of exchange is premised on a misunderstanding of the role of power. Market exchange is always balanced in a sense that the exchange point $(x, y)$ is a zero-sum point where an improvement in the conditions of one party must come at the detriment of another. The imbalance discovered by Emerson and others, which is caused by additional load, falls on the balance of exchange from party A's side. It is the power that A holds. Therefore, A can surrender less of the product, relative to a situation in which their power is absent. Thus, Emerson adds support to the proposition that it is power that is compared during the exchange. The weight of party A's power tips the ratio in their favor without disturbing the balance of exchange.

I mentioned that various researchers have distinguished between manifestations of power, such as coercion and agreement. As far as generalized power and exchange are concerned, power often manifests in agreements. However, if the terms of the exchange are violated or left unfulfilled, methods of social coercion and punishment can be applied. Thus, the exercise of power in exchange includes both contractual and coercive components.

Returning to the original exchange problem given by the system of equations (3), the power exchange theory provides the objective equilibrium equation $\mathrm{OB}$ for the general system.

$O B(x, y)=B_{1}(x)-B_{2}(y)=0(7)$ 
From this, a system of exchange equations can be obtained.

$$
\left\{\begin{array}{c}
B_{1}(x)-B_{2}(y)=0 \\
\varphi_{1}(a-x) \psi_{2}(b-y)-\varphi_{2}(x) \psi_{1}(y)=0
\end{array} .\right.
$$

In fact, the first equation permits the determination of the objective proportion of exchange (price). The second equation compares this proportion (price) with the subjective scale of marginal utility and allows the absolute values of the variables $x$ and $y$ to be calculated. Earlier in the paper, I mentioned Walras and Jevons' exchange theories, in which additional conditions were employed to obtain a solution. Now, it can be said that these selfsame conditions are given by the objective equilibrium equation (7). Recall how Edgeworth, who criticized Jevons and Walras, pointed out that the exchange problem described by the corresponding equations is solved under perfect competition, that is, when the number of agents in the market tends to infinity (Edgeworth 1881). According to the power theory of exchange, in the case of a large market, the equation (7) for each individual exchange is subject to much greater social influences due to competition. This influence reduces the differences between the various possible equations (7) for the same type of object, reduces the existing price dispersion. However, even in a large market, a variety of prices is always possible. The price may depend on the individuals participating in the exchange, on their social status and connections, and on many other circumstances, the assessment of which is made when comparing the generalized power during the exchange. How do the $\mathrm{OB}$ equations for individual exchanges relate to the averaged Walrasian price equations?

If there are $\mathrm{N}$ exchanges on the market, then for each one we have the equation: $\mathrm{B}_{1 i}\left(x_{i}\right)=\mathrm{B}_{2 i}\left(y_{i}\right)$, where $0<=\mathrm{i}<\mathrm{N}$. To go to the price view, let's perform the transformations: 
$\left(\frac{\mathrm{B}_{1 i}\left(x_{i}\right)}{x_{i}}\right) x_{i}=\left(\frac{\mathrm{B}_{2 i}\left(y_{i}\right)}{y_{i}}\right) y_{i}$ or $x_{i}=\left(\frac{\mathrm{B}_{2 i}\left(y_{i}\right) x_{i}}{\mathrm{~B}_{1 i}\left(x_{i}\right) y_{i}}\right) y_{i}$. Let us introduce the following notation for the coefficient at $\mathrm{y}: x_{i}=p_{21 i}\left(x_{i}, y_{i}\right) y_{i}$. If to sum up these exchange conditions for the entire market, we get: $\sum_{0 \leq i<N} x_{i}=\sum_{0 \leq i<N} p_{21 i}\left(x_{i}, y_{i}\right) y_{i}$. In this case, the supply of product A on the market will be $O_{a}=\sum_{0 \leq i<N} x_{i}$ (in Walras's book, the supply is indicated by the letter O), and the supply of product B: $O_{b}=\sum_{0 \leq i<N} y_{i}$. Hence:

$O_{a}=\left(\frac{\sum_{0 \leq i<N} p_{21 i}\left(x_{i}, y_{i}\right) y_{i}}{\sum_{0 \leq i<N} y_{i}}\right) O_{b}$

Thus, for a global Walrasian price, we get:

$p_{b}=\left(\frac{\sum_{0 \leq i<N} p_{21 i}\left(x_{i}, y_{i}\right) y_{i}}{\sum_{0 \leq i<N} y_{i}}\right)=\frac{1}{p_{a}}(8.1)$

Note that Walras did not consider supply (O) but demand (D) as the primary factor (Walras 2000). Mathematically, this does not matter, since at the moment of exchange the values of $\mathrm{O}$ and $\mathrm{D}$ are equal. This is more like the question "which came first, the egg or the chicken." However, judging by the above reasoning for the justification of equation (7), the supply looks as primary for determining the price, since what is given is measured.

This way, all of the different equations (7) for individual exchanges can be aggregated into a single exchange ratio equation for all market participants (8.1). This ratio appears to be the very market price that Walras took for granted. Then Walrasian "one price" gives rise to Jevons' law of indifference because if there is fixed price than "all portions must be exchanged at the same ratio" (Jevons 1924). Under the circumstances suggested by Jevons and Walras, equation (7) provides the very conditions that they needed in order to obtain results.

Returning to exchange, its ratio may be influenced by various intrinsic properties of the object. The object of exchange can have many properties but not all are relevant to particular exchanges. I will call the relevant properties exchangeable. An object can be considered as a set of exchangeable properties because its other qualities play no role. 
Thus, within the framework of the exchange:

$\mathrm{O}=\{\mathrm{M} 1, \mathrm{M} 2, \mathrm{M} 3, \ldots \mathrm{Mn}\}$, where Mi are the exchangeable properties of the object $\mathrm{O}$. (9)

It is important to note that function $\mathrm{B}=\mathrm{B}(\mathrm{H}, \mathrm{O})$ depends not only on the properties of the exchange object, but also on its owner's personality (H1, H2). The qualities of the exchange participant, both personal and public, play an important role in establishing the value of $\mathrm{B}$. Therefore, the participant's personality affects the exchange ratio. Equation (7) does not establish the absolute value of the function B but only a ratio of quantities. However, there is an object of exchange that allows the absolute value of the function to be measured, and that object is money.

\section{A Power Theory of Money}

In this study, I define money as an object of exchange that only has one exchangeable property, quantity, which is a positive number. On the one hand, this definition implies that money has a certain exchange value because it is an object of exchange, that is, because people are ready to accept it in exchange for something else. On the other hand, money is defined as an abstract, imaginary object, a number. This approach resonates with John Maynard Keynes's view of the nature of money. In his book "Treatise On Money" he stated that "money-of-account is the description or title" or "name or description in the [money] contract", so money acts as an abstract name for an accounting unit. (Keynes 1914) Economic practice increasingly shows that money is a number. Indeed, most of the money in circulation in the world today comprises numbers stored in the memories of computers. Estimates suggest that the share of cash is $9-15 \%$ in some countries. (Bruno et al. 2020) Even if the appearance of paper dollars is easy to distinguish from that of paper euros, dollars and euros are completely identical in their digital forms. 
The invention of cryptocurrency has advanced the conceptualization of money as a number. When fiat currency is used, numbers are stored on special banking computers. In the case of cryptocurrency, the ledger is distributed among many computers across the globe. The numbers are not even stored securely on computers owned by the central bank of some country. However, cryptocurrency is a medium of exchange. In this way, it is just like any other currency.

That money is simply a number means that it can be used to measure generalized power. The condition of the exchange is that the magnitude of the generalized power of the two parties be equal. When object $\mathrm{O}$ is exchanged for money $\mathrm{D}$, then the exchange condition is

$\mathrm{B}(\mathrm{H} 1, \mathrm{O})=\mathrm{B}(\mathrm{H} 2, \mathrm{D}) .(11)$

Moreover, money has only one exchange property, the amount $\mathrm{K}$.

$\mathrm{D}=\{\mathrm{K}\}$ means $\mathrm{B}(\mathrm{H} 1, \mathrm{O})=\mathrm{B}(\mathrm{H} 2,\{\mathrm{~K}\})$

It was shown earlier that bargaining does not establish the absolute value of $\mathrm{B}$ but a ratio. As a result, absolute values can be set arbitrarily without loss of generality. According to the definition of money given above, there is a special object of exchange which is a number itself. It is this number, the amount of money, that serves naturally as a measure of the magnitude of generalized power. The assumption is that

$\mathrm{B}(\mathrm{H} 2,\{\mathrm{~K}\})=\mathrm{K}$, and then

$\mathrm{B}(\mathrm{H} 1, \mathrm{O})=\mathrm{K}$.

The implication is that the amount of money that is exchanged for object $\mathrm{O}$ measures the amount of generalized power that binds participant $\mathrm{H} 1$ to object $\mathrm{O}$. I conclude that 
money measures the generalized power that a participant in an exchange has in relation to the object.

However, this proposition does not exhaust the role of money. In exchanging the object $\mathrm{O}$ for money $\mathrm{D}$, participant $\mathrm{H} 1$ obtains the opportunity to use generalized power in the amount of $\mathrm{K}$ units in subsequent exchanges. Accordingly, money is not only measuring generalized power in the course of exchange, but it also attests (certifies, confirms, denotes, symbolizes, serves as an equivalent) the corresponding amount of generalized power in subsequent exchanges.

Thus, a power theory of money was built. The main purpose of money is the measurement and certification of generalized power. The relationship between money and power has already been the subject of scientific research before. The well-known American sociologist Talcott Parsons made a significant contribution to the field. In his article "On the concept of political power," Parsons demonstrates the parallel between money and power. He wrote: "I conceive power as such a generalized medium in a sense directly parallel in logical structure, though very different substantively, to money as the generalized medium of the economic process." (Parsons 1963) His approach underscores the analogy between power in the political system and money in the economic system.

If power is quantifiable and not a zero-sum game, then it can be created and erased. It was seen that this is exactly what happens when objects are transferred at the point of exchange. Generalized power over one object disappears, and generalized power over another object appears. There is no reason to suppose that the magnitude of the new power is equal to that of the previous one. Moreover, it is noticeable from the very type of the power function

$\mathrm{B}=\mathrm{B}(\mathrm{H}, \mathrm{O})$ 
that the value of $\mathrm{B}$ depends on the exchange participant $\mathrm{H}$ in the same way in which it depends on the subject of exchange O. I noted that equation (7) is objective. It may be thought that this statement contradicts the proposition that the function B depends on the personality of $\mathrm{H}$, which can be understood as a subjective factor. However, that argument is false. The value of the function B shows the magnitude, figuratively speaking, of the "force of gravity" between the person $\mathrm{H}$ and the object $\mathrm{O}$, which is measured objectively through bargaining. The value of the function B is set in a clash between the interests of different parties, a tug of war of sorts, where each tries to tear something away from the other. In other words, neither side is willing to allow the other to establish their desired value of $B$. The value of $B$ depends on a person in the same way as, for example, height or weight. However, being measured objectively, it is objective.

Conversely, in the Jevons exchange equation (4), the participants in the exchange set the values of the marginal utility functions exclusively. Moreover, the sides of equation (4) equate not the absolute values of the marginal utility functions of the participants but their ratios. In fact, in equation (4), both the left- and the right-hand side are the marginal exchange rates (or marginal rate of substitution) of the corresponding goods as measured by the internal coordinate systems of each participant. In other words, the values that are being equated are purely subjective. The left-hand side represents the marginal proportion in the "system of measuring the utility" for the first participant, $\left(\frac{\varphi_{1}(a-x)}{\psi_{1}(y)}\right)$, and $\left(\frac{\varphi_{2}(x)}{\psi_{2}(b-y)}\right)$ performs the same function for the second participant on the right-hand side.

If there is an exchange which is conditional on equality

$\mathrm{B}(\mathrm{H} 1, \mathrm{O} 1)=\mathrm{B}(\mathrm{H} 2, \mathrm{O} 2)$

then after the exchange, once $\mathrm{O} 2$ has passed to the power of $\mathrm{H} 1$ and $\mathrm{O} 1$ has passed to the power $\mathrm{H} 2$, it will generally be the case that 
$\mathrm{B}(\mathrm{H} 1, \mathrm{O} 2) \neq \mathrm{B}(\mathrm{H} 2, \mathrm{O} 1)$. (This can be understood to mean that there are no conditions for the reverse exchange). Moreover, $\mathrm{B}(\mathrm{H} 1, \mathrm{O} 1) \neq \mathrm{B}(\mathrm{H} 1, \mathrm{O} 2)$ as well as $\mathrm{B}(\mathrm{H} 2, \mathrm{O} 2) \neq \mathrm{B}(\mathrm{H} 2$, O1).

The actual values of the resulting generalized power on both sides can only be measured during the next exchange - it is unknown in the immediate aftermath of the transfer. Consumption cannot be the sole purpose of the exchange, and subsequent exchange for profit must also feature. It follows from previous reasoning that if a person $\mathrm{H} 1$ exchanges object $\mathrm{O} 1$ for $\mathrm{O} 2$ in order to make a profit, then their motivation is tied to the expectation that their generalized power will grow after the exchange.

$\mathrm{B}(\mathrm{H} 1, \mathrm{O} 1)<\mathrm{B}(\mathrm{H} 1, \mathrm{O} 2)$.

This explanation also shows how profit is obtained in trading operations. The art of the merchant is to assess fluctuations in the magnitude of generalized power correctly.

It is worth dwelling briefly on the issue of trading profit. If a merchant buys A for money D1 and than sells the same A for money D2, than "profit" means that D2 $>$ D1. Suppose that objective condition of exchange $\mathrm{OB}$ is represented by a function $\mathrm{F}$, which depends only on the object of exchange $\mathrm{O}: \mathrm{F}=\mathrm{F}(\mathrm{O})$. In this case for trade operations of the merchant will be: $F(A)=F(D 1)$ - this is the condition of the first exchange and $F(A)=F(D 2)$ is for the second exchange. From this follows: $F(D 1)=F(D 2)$, what is impossible (D2>D1). It looks like if the objective condition of exchange OB depends only on the object of exchange, than trade profit is impossible. But in reality, trading profits exist. This means that such functions, dependent only on $\mathrm{O}$ but independent on $\mathrm{H}$, cannot be used to model exchange. For example such functions measure labor in LTV and scarcity in Walras theory. 
Power can be transferred and created. This is true of all types of power, including symbolic power in the form of money. In the world of money, the phenomenon of the transfer of power is called credit. When a loan is issued, symbolic power in the form of money is transferred to the borrower's temporary use on predetermined conditions. The beneficiary of the loan disposes with the corresponding generalized power for some time. Basically, lending is a business of banks. Importantly, in order to issue a loan, a bank does not need to have same amount of money. Some banks have the right to issue loans if they hold a fractional reserve of funds. In other words, if the bank holds a certain amount of money in reserve, it can issue an amount of credit far in excess of the reserves. Classical researchers called the phenomenon of new money creation by banks money multiplier. Today this approach is under great criticism. (Carpenter \& Demiralp 2012) Criticism argues that today the mechanism for creating new money by banks is different, since the initial premise for a loan is not the availability of a reserve, but the existing demand for loans. (McLeay 2014) For this study, it is not important how it works. The fact is that this mechanism exists. Thus, in the banking system, economic power in monetary form is created and distributed. Parsons came to similar conclusions about the parallel between power creation and money creation. He demonstrated that there are analogies between the emergence of new power and the creation of new money through the "credit multiplier." (Parsons 1963)

This concludes the summary of the main elements of the power theory of exchange and money.

\section{Conclusion}

The present article proposed a formulation of the exchange problem in the form of a system of two equations with two unknowns. One of the equations represents objective conditions of exchange, and the other equation represents subjective conditions of exchange. This approach resolves the long-standing dispute between two approaches to 
the exchange model, MUT and LTV. These theories are viewed as competing, but it transpires that they represent different and complementary conditions of exchange: MUT represents subjective circumstances, while the LTV represents objective ones. It may appear that combining the two approaches would solve the exchange problem, but as noted in paper the LTV is incomplete and it is refuted by simple counterexamples. Therefore, to establish the objective conditions of exchange, I proposed another idea whereby the objective basis of exchange is the comparison of generalized power. This idea gives rise to a power theory of exchange that is complete and that applies to any exchange. In addition to explaining the nature of exchange, the power theory captures the essence of money. Money turns out to be a measure and a certificate of generalized power in exchange.

As noted, some thoughts set out in this article are found in economic and sociological research in scattered and partial form. However, it is only when they are collated into a power theory of exchange that these thoughts coalesce into a single logical fabric. Moreover, the connection and interdependence between economic, sociological and political theories becomes clear. The further development of the power exchange theory will enable a deeper examination of both economic and socio-political phenomena.

\section{References}

Aristotle. 1906. The Nicomachean Ethics of Aristotle. Translated by F.H. Peters. Tenth Edition London: Kegan Paul, Trench, Trubner \& Co.

Baldwin, David A. 1971. "Money and Power". The journal of politics, Vol. 33

Böhm-Bawerk, Eugen von. 1886. Grundzude der Theorie des wirtschaftlichen

Gutenwerts. Conrads Jahrbucher fur Nationaloekonomie und Statistik (de).

Blau, Peter Michael. 1964. Exchange and Power in Social Life. John Wiley \& Sons, Inc. Bruno, Philip and Olivier Denecker, Marc Niederkorn. 2020. The 2020 McKinsey Global Payments Report 
Carpenter, Seth and Selva Demiralp. 2012. "Money, reserves, and the transmission of monetary policy: Does the money multiplier exist?" Journal of Macroeconomics, Volume 34, Issue 1, 59-75

Donzelli, Franco. 2011. "Negishi on Edgeworth on Jevons's law of indifference, walras's equilibrium, and the role of large numbers: a critical assessment" Cahiers d économie Politique / Papers in Political Economy 63(2)

Edgeworth, F. Y. 1881. Mathematical psychics, an essay on the application of mathematics to the moral sciences. London: C. Kegan Paul \& CO.

Emerson, Richard M. 1976. "Social Exchange Theory." Annual Review of Sociology, Vol. 2, pp. 335-362

Grossman, S and O Hart. 1986. "The Costs and Benefits of Ownership: A Theory of Vertical and Lateral Integration", Journal of Political Economy 94(4): 691-719.

Hearn, Jonathan. 2012. Theorizing power. Palgrave Macmillan.

Jevons, W. Stanley. 1924. The theory of political economy, Fifth edition. London: Macmillan and. Co.

Kahneman, Daniel. 2011. Thinking, fast and slow. Farrar, Straus and Giroux.

Keller, Lech. 2015. "The Problem with the Concept of Utility and its Measurement". Polish Journal of Political Science, Vol. 1, Issue 4

Keynes, John Maynard. 1914. A treatise on money. Volume I. The pure theory of money. London: Macmillan and Co., Limited

Kuznetsov, A.G. 2012. "Sociological interpretations of power in the theory of social exchange." Vlast magazine (ru)

Ledyaev, V.G. 2015. "Modern concepts of power: an analytical review" Sociological journal (ru). 3-4. S. 109-126.

Marshall, Alfred. 1890. Principles of Economics (8th ed.). London: Macmillan and. Co.

Marx, Karl. 1867. Das Kapital. Kritik der politischen Oekonomie. Erster Band. Hamburg: Verlag von Otto Meissner.

Mills, Charles Wright. 1956. The the Power Elite. New York: Oxford University Press Mises, Ludwig von. 1998. Human action. A Treatise on Economics. Auburn: Ludwig von 
Mises institute

McLeay, Michael, Amar Radia and Ryland Thomas of the Bank's Monetary Analysis

Directorate. 2014. "Money creation in the modern economy". Bank of England Quarterly Bulletin 2014 Q1

Negishi, Takashi. 1989. History of Economic Theory. North Holland.

Palermo, Giulio. 2016. Economics and power: a Marxist critique. New York: Routledge Parsons, Talcott. 1963. "On the Concept of Political Power". Proceedings of the American Philosophical Society, Vol. 107, No. 3 (Jun. 19, 1963), pp.232-262

Russell, Bertrand. 2004. Power: A New Social Analysis. Basingstoke: Palgrave Macmillan.

Walras, Leon. 1954. Elements of pure economics or the theory of social wealth. London: George Allen and Unwin ltd Weber, Max. 1957. The theory of social and economic organization. The Free Press. 